\title{
ADVANCED NANOHYBRID FORMULATION OF THE SPARINGLY SOLUBLE DRUG SULINDAC FOR CONTROLLED RELEASE STUDIES
}

\author{
KEIJI MINAGAWA \\ Institute of Technology and Science, The University of Tokushima, \\ Tokushima 770-8506, Japan. \\ minagawa@chem.tokushima-u.ac.jp \\ MOHAMED R. BERBER \\ Department of Chemistry, Faculty of Science, Tanta University, \\ Tanta 31527, Egypt. \\ mrberber@science.tanta.edu.eg \\ INAS H. HAFEZ \\ Institute of Technology and Science, The University of Tokushima, \\ Tokushima 770-8506, Japan. \\ Ihazzaa@sy34.chem.tokushima-u.ac.jp \\ TAKESHI MORI \\ Department of Applied Chemistry, Kyushu University, \\ Fukuoka 819-0395, Japan. \\ mori.takeshi.880@m.kyushu-u.ac.jp \\ MASAMI TANAKA \\ Faculty of Pharmaceutical Sciences, Tokushima Bunri University, \\ Tokushima 770-8514, Japan. \\ tanaka@ph.bunri-u.ac.jp
}

\begin{abstract}
We offered an advanced nanohybrid formulation system of Sulindac (SUL) based on layered double hydroxide (LDH) nanoparticles. The formulated materials were characterized by X-rays, Infrared and SEM techniques to confirm the nanohybrid structure. The drug incorporation ratio was determined to be $45 \%$. The drug solubility was improved after the LDH nanohybrid formation. The anion-exchange mechanism of $\mathrm{LDH}$ supported the dissolution process for the intercalated SUL.
\end{abstract}

Keywords: Nanohybrid; sulindac; LDH.

\section{Introduction}

Non-steroidal anti-inflammatory drug (NSAIDs) are drugs with analgesic and antipyretic effects. Sulindac (SUL) is a NSAID of acetic acid derivatives. It relieves the pain, 
tenderness, inflammation and swelling ${ }^{1,2}$. However SUL is a sparingly soluble drug and aqueous solubility is a major indicator for the drug activity in the intestinal fluids and the potential contribution to bioavailability issues. Therefore, the solubility and dissolution of SUL should be addressed and controlled carefully through an advanced formulation system. Furthermore, SUL has a carboxylic acid group that can impart local gastrointestinal irritation through the direct contact with mucous membrane ${ }^{3}$. To improve SUL dissolution properties, several approaches were reported for example solid dispersions with polyvinyl pyrrolidone $e^{4}$ and complexation with cyclodextrins ${ }^{5}$. However these formulations are using complicated and technically challenging processes. Thus, more advances formulations of SUL with controlled delivery doses are required. An innovative approach of oral drug delivery involves the use of layered double hydroxides (LDHs) nanoparticles as drug carriers. This new platform offers many potential advantages over the traditional oral drug delivery systems.

LDHs are a family of natural and synthetic compounds. LDH consists structurally of brucite-like sheet with hexagonal-shaped crystallite layers ${ }^{6}$. It can be prepared in laboratory by different techniques ${ }^{7-9}$. LDH possess excellent biomedical properties such as chemical inertness, null toxicity, biocompatibility, and antacidic and antipyretic properties $^{10}$. Consequently, they can be used as drug matrixes, drug stabilizers during storage and drug delivery carriers.

Based on our knowledge, there is no report concerning the formulation of SUL in a form of nanohybrid. Here, we report the synthesis and characterization of a new formulation system of SUL-nanohybrid based on LDH materials. Subsequently, we study the solubility issue form the nanohybrid to evaluate the effect of LDH on SUL properties after the intercalation process.

\section{Experimental work}

\subsection{Materials}

$\mathrm{Mg}\left(\mathrm{NO}_{3}\right)_{2} \cdot 6 \mathrm{H}_{2} \mathrm{O}, \mathrm{Al}\left(\mathrm{NO}_{3}\right)_{3} \cdot 9 \mathrm{H}_{2} \mathrm{O}$ (Wako Pure Chemical Industries, Ltd.) and SUL high grade (Sigma Chemical Co.,) were used as received. All solutions were prepared using deionized water (18.2 M $\Omega / \mathrm{cm}$, produced from Milli-Q Grandient ZMQG000kt).

\subsection{Nanohybrid formulation of $S U L-L D H$}

\subsubsection{Synthesis of $\mathrm{MgAl}-\mathrm{NO}_{3} \mathrm{LDH}$}

To a round flask containing $30 \mathrm{~mL}$ of $1.0 \mathrm{M} \mathrm{NaNO}_{3}$ solution was added dropwise a $50 \mathrm{~mL}$ solution of $8.538 \mathrm{~g}(0.0333 \mathrm{M})$ of $\mathrm{Mg}\left(\mathrm{NO}_{3}\right)_{2} \cdot 6 \mathrm{H}_{2} \mathrm{O}$ and $6.249 \mathrm{~g}(0.01666 \mathrm{M})$ of $\mathrm{Al}\left(\mathrm{NO}_{3}\right)_{3} \cdot 9 \mathrm{H}_{2} \mathrm{O}\left(\mathrm{Mg}^{2+} / \mathrm{Al}^{3+}=2\right)$ with constant stirring. During the metal ion addition, the $\mathrm{pH}$ of the suspension was kept constant at 8.0 by adding appropriate amounts of $2.0 \mathrm{M}$ $\mathrm{KOH}$ solution. The final volume of the preparation medium was augmented to $100 \mathrm{~mL}$ by deionized water. The resultant suspension was stirred at $70{ }^{\circ} \mathrm{C}$ for $24 \mathrm{~h}$ under $\mathrm{N}_{2}$ flow. At 
the end of the reaction, the formed $\mathrm{Mg}-\mathrm{Al} \mathrm{LDH}$ material was collected by filtration, washed several times with deionized water, and finally freeze-dried.

\subsubsection{Preparation of SUL nanohybrid}

To a round flask, $1.0 \mathrm{~g}$ of SUL was dissolved in $60 \mathrm{~mL}$ deionized water by adjusting the solution $\mathrm{pH}$ to 8.0 using $2.0 \mathrm{M} \mathrm{KOH}$ solution. A $30 \mathrm{~mL}$ aqueous solution containing $8.538 \mathrm{~g} \mathrm{Mg}\left(\mathrm{NO}_{3}\right)_{2} \cdot 6 \mathrm{H}_{2} \mathrm{O}$ and $6.249 \mathrm{~g} \mathrm{Al}\left(\mathrm{NO}_{3}\right)_{3} \cdot 9 \mathrm{H}_{2} \mathrm{O}$ was added dropwise with constant stirring to the drug solution. During the metal ion addition, the $\mathrm{pH}$ of the suspension was kept constant at 8.0 by adding appropriate amounts of $2.0 \mathrm{M} \mathrm{KOH}$ solution. The final volume of the preparation medium was augmented to $100 \mathrm{~mL}$ by deionized water. The resultant suspension was stirred at $70^{\circ} \mathrm{C}$ for $24 \mathrm{~h}$ under $\mathrm{N}_{2}$ flow. At the end of the reaction, the formed SUL-LDH material was collected by filtration $(0.45-\mu \mathrm{m}$ Millipore membrane), washed several times by $0.1 \mathrm{M} \mathrm{KOH}$ solution and subsequently deionized water until a negative test was obtained for drug in the washing medium. A UV spectrophotometer (U-3210, Hitachi, Japan) was used to check for the presence of SUL in the washing medium at $254.0 \mathrm{~nm}$. Finally, the collected SUL-LDH material was freeze-dried.

\subsection{Characterization and measurements}

$\mathrm{X}$-ray powder diffraction patterns were recorded on a Rigaku X-ray diffractometer using $\mathrm{CuK} \alpha$ radiation at $\lambda=1.5405 \AA$. The measurement was performed in the $2 \theta$ range $1.5-70^{\circ}$ with a $2 \theta$ scanning step of $0.02^{\circ}$, a scanning step time of $5 \mathrm{~s}$, a filament intensity of $40 \mathrm{~mA}$, and a voltage of $150 \mathrm{kV}$. Infrared spectra (KBr disk method) were recorded on a Bio-Rad FTS 3000MX FT-IR spectrophotometer. The TGA was conducted with a Shimadzu thermogravimetric analyzer (TGA-50, TA-60WS) under a $\mathrm{N}_{2}$ flow of $20 \mathrm{~mL} / \mathrm{min}$. The scanning electron micrographs (SEM) were captured by a Hitachi FE-SEMS-4700 microscope.

The incorporation ratio of SUL (the amount of drug intercalated per a unit weight of hybrid material) was determined as follows. The amount of SUL incorporated into LDH was calculated by using a UV quantitative method as follows. A known amount of the hybrid material was dissolved in $10.0 \mathrm{~mL}$ of $1.0 \mathrm{M} \mathrm{HCl}$ solution. The obtained solution was diluted using a phosphate buffer of $\mathrm{pH}$ 7.4. SUL concentration was determined from UV-absorption peak at $254.0 \mathrm{~nm}$. SUL incorporation ratio was expressed by the percentage of SUL weight intercalated into a unit weight of hybrid. The UV method was also used to check the integrity of SUL after the intercalation process.

The solubility experiment was performed as follows: In a round-bottom flask, a sample of $100.0 \mathrm{mg}$ of SUL or $200.0 \mathrm{mg}$ of SUL-LDH nanohybrid was dispersed in $100 \mathrm{~mL}$ of buffer (a $100 \mathrm{~mL}$ solution mixture of $100.0 \mathrm{mM} \mathrm{HCl}$ and $100.0 \mathrm{mM} \mathrm{KCl}$; a few drops of $10.0 \mathrm{mM} \mathrm{HCl}$ solution was used to adjust the solution $\mathrm{pH}$ at 2.0), which was maintained at $36.8 \pm 0.1^{\circ} \mathrm{C}$ with constant agitation of $80 \mathrm{rpm}$. At appropriate time intervals, a $1.0 \mathrm{~mL}$ sample solution was withdrawn from the release medium and filtered 
by using a $0.45 \mu \mathrm{m}$ Millipore filter unit to remove the insoluble particles. Then, the filtrate was diluted and assayed for UV measurement. The removed aliquot was immediately replenished by the same volume of the used buffer, which was equilibrated at the same reaction temperature. The dissolution experiment of each sample was performed in duplicates.

\section{Results and discussion}

Successfully, the used synthetic technique showed SUL-LDH hybrids. The incorporation ratio was determined to be $45 \%$. The elemental analysis showed a $10.83 \% \mathrm{Mg}, 5.65 \% \mathrm{Al}$ by using titration, and $44.98 \% \mathrm{C}$ and $4.77 \% \mathrm{H}$. Accordingly, the composite formula is $\mathrm{Mg}_{0.66} \mathrm{Al}_{0.34}(\mathrm{OH})_{2}(\mathrm{SUL})_{0.30} \cdot \mathrm{XH}_{2} \mathrm{O}$. The $\mathrm{SEM}$ was used to investigate the nanohybrid structure of the prepared materials. Figure 1 displays the SEM images of the synthesized $\mathrm{NO}_{3}$-LDH material and SUL-LDH hybrids. Image a shows uniform and regular hexagonal platelets characteristic for LDH particles. The regularity of the LDH particles confirmed the good crystallinity recorded by X-ray measurement (X-ray section). The LDH particles size was recorded in the nanoscale. In the case of SUL-LDH hybrid (images b), aggregates composed of small nanoparticles were observed. The aggregation process is probably due to a hydrophobic interaction of the LDH surface-adsorbed SUL.
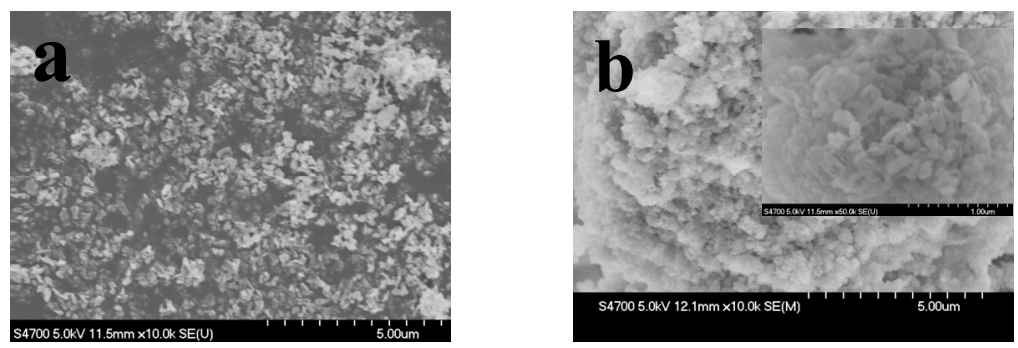

Fig. 1. SEM images of $\mathrm{NO}_{3}-\mathrm{LDH}$ (a) and SUL-LDH (b) hybrids

Figure 2 shows the XRD patterns of LDH and SUL-LDH nanohybrid. The green Pattern indicated the formation of $\mathrm{NO}_{3}$ form of $\mathrm{LDH}$ with sharp and symmetric (00l) reflections. Using Bragg's law, the d003-spacing was calculated to be $8.9 \AA$. As a result of intercalation of SUL (orange pattern), the basal spacing was expanded to $29.4 \AA$. The SUL-LDH interlayer distance was calculated by subtracting the inorganic layer thickness $(4.8 \AA)^{11}$ from the basal spacing. The determined value was $24.6 \AA$. The interlayer distance of SUL-LDH was larger than SUL molecular length $(18.9 \AA)$. However LDH attaches its interlayer anions through an electrostatic interaction ${ }^{12}$, we speculated that SUL molecules were stacked into LDH as a monolayer of interdigitated arrangement through the attachment of SUL carboxyl groups with the LDH positive layers. The X-ray pattern of the sample collected from the releasing medium indicated an anion exchange process of the intercalated drug. The 003 peak of $\mathrm{CO}_{3}$ was detected at $2 \theta$ of 11.6.

FT-IR spectroscopy was used to verify the presence of the intercalated SUL and to gather information about the nanohybrids' molecular structure. In the case of $\mathrm{NO}_{3}-\mathrm{LDH}$ (Figure 3), the lattice vibration modes $\left(v_{\mathrm{M}-\mathrm{O}-\mathrm{M}}, v_{\mathrm{M}-\mathrm{O}}\right)^{13}$ at 550,630 , and $780 \mathrm{~cm}^{-1}$ and the 
asymmetric stretching band of the interlayer nitrate $(v \mathrm{NO} 3)$ at $1360 \mathrm{~cm}^{-1}$ as well as the stretching vibration mode of the hydroxyl groups of LDH layers ${ }^{14}$ at $3440 \mathrm{~cm}^{-1}$. The FT-IR spectrum of SUL showed complex features below $1500 \mathrm{~cm}^{-1}$, which can be attributed to the bending and stretching of aromatic rings, carbon-carbon, and carbon-oxygen bonds. The stretching vibration band of $\mathrm{COOH}$ group was detected at $1610 \mathrm{~cm}^{-1}$. The weak stretching vibration modes of SUL alkyl groups $\left(v_{\mathrm{C}-\mathrm{H}}\right)$ were detected at $3000 \mathrm{~cm}^{-1}$. As a result of intercalation of SUL into LDH, new bands are emerged such as symmetric and asymmetric modes of $\mathrm{COO}^{-}$at 1560 and $1740 \mathrm{~cm}^{-1}$, respectively ${ }^{15}$, besides the characteristic bands of SUL and LDH. In conclusion, the molecular structure information of SUL-LDH nanohybrid indicated that SUL molecules are intercalated into the gallery of LDH.

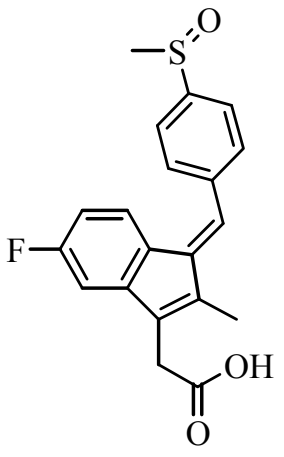

Sulindac

Chart 1. SUL molecular structure

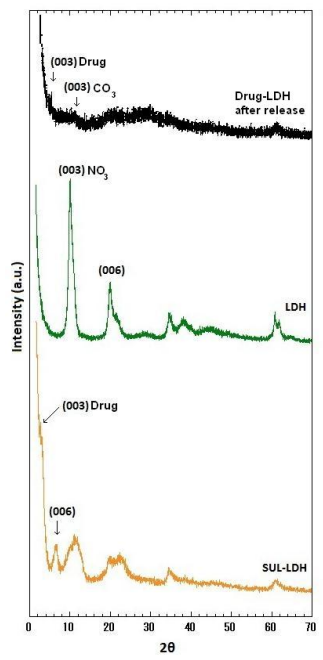

Fig. 2. X-ray diffraction patterns

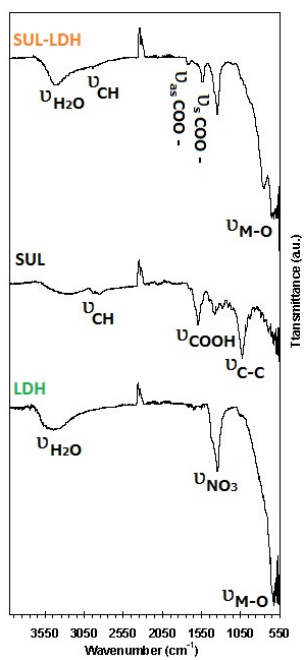

Fig. 3.Infrared spectra

The TGA study (figures are not displayed because of pages limit) showed significant changes in the thermal behavior of SUL before and after intercalation with LDH. After the intercalation, the amount of interlayer water was decreased, probably due to the hydrophobic nature of the intercalated SUL. The overall weight loss was increased from $51 \%$ to $69 \%$ in the final stage. The onset temperature of SUL decomposition shifted to a higher value (from $175^{\circ} \mathrm{C}$ to $225^{\circ} \mathrm{C}$ ). Accordingly, the stability of SUL was promoted against thermal decomposition after the LDH nanohybrid formulation.

Figure 4 shows the solubility of SUL drug and SUL-LDH nanohybrid. The solubility of SUL before intercalation (blue pattern) was very small $(\sim 40 \mathrm{mg} / \mathrm{L})$ due to the acidic character of SUL, indicating the uncontrollable dissolution of SUL after administration. Figure 4 (red pattern) shows the release of SUL from LDH nanohybrid. SUL is a crystalline acidic drug. It has a small solubility in the acidic stomach due to the small dissociation of the crystalline molecules. Significant change in the amount of SUL dissolved with time progress was observed after the composite formation. More than 
three times increase in the solubility of SUL was recorded in a controlled manner. The release of the intercalated SUL depended on both medium anionic species and LDH nanohybrid properties. The layered molecular structure of LDH limited the intercalation of SUL into two-dimensional directions. Such kind of stacking process prevented the crystallization of SUL into the gallery of LDH. As a consequence, SUL was released in an amorphous form suitable for dissolution.

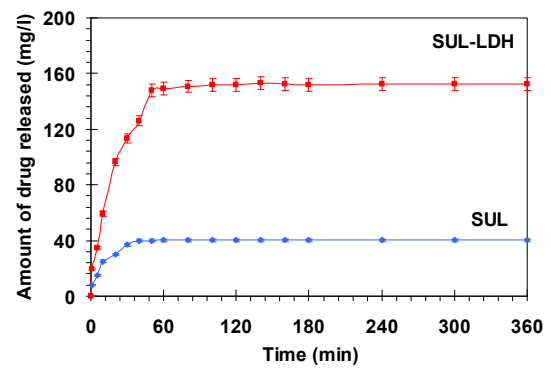

Fig. 4. The dissolution of pure SUL and SUL-LDH nanohybrid

\section{References}

1. S. J. Shiff and B. Rigas, Gastroenterology 113, 1992 (1997).

2. C. V. Rao, A. Rivenson, B. Simi, E. Zang, G. Kelloff, V. Steele and B. S. Reddy, Cancer Res. 55, 1464 (1995).

3. N. M. Davies, and J. L. Wallace, J. Gastroenterol. 32 (1), 127 (1997).

4. M. C. Tros de Ilarduya, C. Martín, M. M. Goñi, and M. C. Martínez-Ohárriz. Drug Dev. Ind. Pharm. 24, 295 (1998).

5. M. C. Tros de Ilarduya, C. Martín, M. M. Goñi and M. C. Martínez-Ohárriz. Drug Dev. Ind. Pharm. 24, 301 (1998).

6. J. W. Boclair, P. S. Braterman, B. D. Brister and F. Yarberry, Chem. Mater. 11 (8), 2199 (1999).

7. S. Miyata, Clays Clay Miner. 28 (1), 50 (1980).

8. Z. Liu, R. Ma, M. Osada, N. Iyi, Y. Ebina, K. Takada and T. Sasaki,. J. Am. Chem. Soc. 128 (14), 4872 (2006).

9. E. Geraud, M. Bouhent, Z. Derriche, F. Leroux, V. Prevot and C. Forano, J. Phy. Chem. Solids 68, 818 (2007).

10. U. Costantino, V. Ambrogi, M. Nocchetti and L. Perioli, Microporous Mesoporous Mat. 107, 149 (2008).

11. S. Miyata, Clays Clay Miner., 23 (1), 369 (1975).

12. U. Costantino, F. Marmottini, M. Nocchetti and R. Vivani, Eur. J. Inorg. Chem. 10, 1439 (1998).

13. Y. Lin, J. Wang, D. G. Evans and D. Li, J. Phys. Chem. Solids 67 (5-6), 998 (2006).

14. J. Olanrewaju, B. L. Newalkar, C. Mancino and S. Komarneni, Mater. Lett. 45(6), 307 (2000).

15. L.-J. MA and Y. WU, Analyt. Sci. 23, 799 (2007). 